NASA/TM-2003-211996/REV1

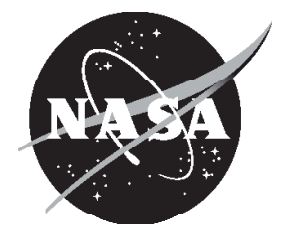

\title{
Permanent Magnetic Bearing for Spacecraft Applications
}

Wilfredo Morales and Robert Fusaro

Glenn Research Center, Cleveland, Ohio

Albert Kascak

U.S. Army Research Laboratory, Glenn Research Center, Cleveland, Ohio 


\section{NASA STI Program . . . in Profile}

Since its founding, NASA has been dedicated to the advancement of aeronautics and space science. The NASA Scientific and Technical Information (STI) program plays a key part in helping NASA maintain this important role.

The NASA STI Program operates under the auspices of the Agency Chief Information Officer. It collects, organizes, provides for archiving, and disseminates NASA's STI. The NASA STI program provides access to the NASA Aeronautics and Space Database and its public interface, the NASA Technical Reports Server, thus providing one of the largest collections of aeronautical and space science STI in the world. Results are published in both non-NASA channels and by NASA in the NASA STI Report Series, which includes the following report types:

- TECHNICAL PUBLICATION. Reports of completed research or a major significant phase of research that present the results of NASA programs and include extensive data or theoretical analysis. Includes compilations of significant scientific and technical data and information deemed to be of continuing reference value. NASA counterpart of peer-reviewed formal professional papers but has less stringent limitations on manuscript length and extent of graphic presentations.

- TECHNICAL MEMORANDUM. Scientific and technical findings that are preliminary or of specialized interest, e.g., quick release reports, working papers, and bibliographies that contain minimal annotation. Does not contain extensive analysis.

- CONTRACTOR REPORT. Scientific and technical findings by NASA-sponsored contractors and grantees.

- CONFERENCE PUBLICATION. Collected papers from scientific and technical conferences, symposia, seminars, or other meetings sponsored or cosponsored by NASA.

- SPECIAL PUBLICATION. Scientific, technical, or historical information from NASA programs, projects, and missions, often concerned with subjects having substantial public interest.

- TECHNICAL TRANSLATION. Englishlanguage translations of foreign scientific and technical material pertinent to NASA's mission.

Specialized services also include creating custom thesauri, building customized databases, organizing and publishing research results.

For more information about the NASA STI program, see the following:

- Access the NASA STI program home page at http://www.sti.nasa.gov

- E-mail your question via the Internet to help@ sti.nasa.gov

- Fax your question to the NASA STI Help Desk at 301-621-0134

- Telephone the NASA STI Help Desk at 301-621-0390

- Write to: NASA Center for AeroSpace Information (CASI) 7115 Standard Drive Hanover, MD 21076-1320 
NASA/TM-2003-211996/REV1

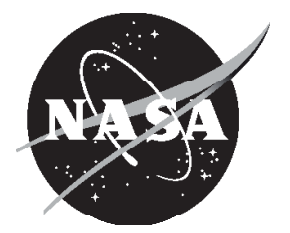

\section{Permanent Magnetic Bearing for Spacecraft Applications}

Wilfredo Morales and Robert Fusaro

Glenn Research Center, Cleveland, Ohio

Albert Kascak

U.S. Army Research Laboratory, Glenn Research Center, Cleveland, Ohio

Prepared for the

2003 Annual Meeting and Exhibition

sponsored by the Society of Tribologists and Lubrication Engineers

New York City, New York, April 28-May 1, 2003

National Aeronautics and

Space Administration

Glenn Research Center

Cleveland, Ohio 44135 


\section{Acknowledgments}

The authors wish to acknowledge the indispensable contributions of Ben Ebihara, Ralph Jansen, and Mark Siebert, Ohio Aerospace Institute, Brook Park, Ohio, and Andrew Kenny, Texas A\&M University, College Station, Texas.

\section{Document Change History}

This printing, numbered as NASA/TM-2003-211996/REV1, January 2008, replaces the previous version, NASA/TM-2003-211996, March 2003, in its entirety. It contains the following changes:

Page ii, Acknowledgments text has been replaced with

The authors wish to acknowledge the indispensable contributions of Ben Ebihara, Ralph Jansen, and Mark Siebert, Ohio Aerospace Institute, Brook Park, Ohio, and Andrew Kenny, Texas A\&M University, College Station, Texas.

Page 1, Introduction, paragraph 2: Siebert, et al. (2002) reference has been inserted so the paragraph reads

Magnetic bearings can be grouped as either active or passive. Actively controlled magnetic bearings operate in the attractive mode. They have the ability to support large loads, they have adjustable bearing characteristics such as stiffness and damping, and dynamic control. However, they are expensive and require complicated control hardware, such as digital signal processors, amplifiers, digital-to-analog converters, analog-to-digital converters, and software. Passive magnetic bearings on the other hand do not require this hardware (Siebert, et al. (2002)). They can be made smaller, more efficient and reliable. The disadvantages of passive magnetic bearing are that they typically have lower stiffness and lower damping than similar size active magnetic bearings, and vibration control cannot be used.

Page 5, Present and Future Work text has been replaced with

This work was led by Robert Fusaro who was able to obtain funding from the Glenn Research Center Director's Discretionary Fund. This work will serve as the basis to hopefully convince the Discretionary Fund Committee to continue further funding in the area of magnetic bearings. If funded, the magnetic bearing rig will be tested at higher rotational speeds, up to 50,000 rpm, to assess vibration problems which are of great concern if magnetic bearings are to be used in spacecraft. Another area of concern is the successful use of mechanical back-up bearings that are simple in design, small in size, and capable of absorbing the high rotational energy of the magnetic bearing without serious damage.

Page 6, the following reference has been inserted:

Siebert, M., Ebihara, B., Jansen, R., Fusaro, R.L., Morales, W., Kasak, A., and Kenny, A., 2002, “A Passive Magnetic Bearing Flywheel,” NASA TM-2002-211159, 2002.

The Propulsion and Power Program at NASA Glenn Research Center sponsored this work.

Level of Review: This material has been technically reviewed by technical management.

Available from

NASA Center for Aerospace Information 7115 Standard Drive Hanover, MD 21076-1320
National Technical Information Service 5285 Port Royal Road Springfield, VA 22161

Available electronically at http://gltrs.grc.nasa.gov 


\title{
PERMANENT MAGNETIC BEARING FOR SPACECRAFT APPLICATIONS
}

\author{
Wilfredo Morales and Robert Fusaro \\ National Aeronautics and Space Administration \\ Glenn Research Center \\ Cleveland, Ohio 44135 \\ Albert Kascak \\ U.S. Army Research Laboratory \\ Glenn Research Center \\ Cleveland, Ohio 44135
}

\begin{abstract}
A permanent, totally passive magnetic bearing rig was designed, constructed, and tested. The suspension of the rotor was provided by two sets of radial permanent magnetic bearings operating in the repulsive mode. The axial support was provided by jewel bearings on both ends of the rotor. The rig was successfully operated to speeds of $5500 \mathrm{rpm}$ using an air impeller. Radial and axial stiffnesses of the permanent magnetic bearings were experimentally measured and then compared to finite element results. The natural damping of the rotor was measured and a damping coefficient was calculated.
\end{abstract}

\section{INTRODUCTION}

Ball bearings are used on satellites for many purposes, including positioning control and scanning equipment operation. Although their use in the vacuum of space has a long history, lubrication has remained a troublesome area especially when longer satellite lifetimes are demanded. Both solid lubricants and liquid lubricants have their pros and cons but neither one appears to minimize sufficiently the friction and wear needed for extended satellite lifetime. Magnetic bearings offer a desirable alternative to the use of ball bearings in a space vacuum. They can operate with near zero friction and wear without the use of lubricant. They can be used over a wide temperature range and exhibit very low vibration.

Magnetic bearings can be grouped as either active or passive. Actively controlled magnetic bearings operate in the attractive mode. They have the ability to support large loads, they have adjustable bearing characteristics such as stiffness and damping, and dynamic control. However, they are expensive and require complicated control hardware, such as digital signal processors, amplifiers, digital-to-analog converters, analog-to-digital converters, and software. Passive magnetic bearings on the other hand do not require this hardware (Siebert, et al. (2002)). They can be made smaller, more efficient and reliable. The disadvantages of passive magnetic bearing are that they typically have lower stiffness and lower damping than similar size active magnetic bearings, and vibration control cannot be used.

For successful operation, a passive magnetic bearing must have sufficient stiffness and damping to perform over its entire operating range. A few studies have been published on the stiffness and damping of passive magnetic bearing systems. Ohji et al. (1999) 
investigated the radial disturbance attenuation characteristics of horizontal and vertical shaft machines supported radially by permanent magnetic bearings. Fremerey (2000) used permanent magnetic bearings with eddy-current damping to levitate a $500 \mathrm{Whr}$ energy storage flywheel for an uninterruptible power supply. Satoh et al. (1996) used a mechanical damper attached to the stator magnets in a system with four axes that are passively levitated. Jansen and DiRusso (1996) measured the stiffness and damping of a ferrofluid stabilizer, and the stiffness of permanent magnetic bearings.

Jewel bearings are widely used in electrical measuring instruments such as galvanometers, ammeters, and energy measuring meters. A jewel bearing consists of a ball that spins on an axis perpendicular to the contact area. Jewel bearings have been treated analytically and experimentally. Sankar and Tzenov modeled the motion accuracy of a jewel bearing (1994a) and determined its steady-state dynamics using a free ball and its motion due to friction (1994b). Spinning ball contact of jewel bearings was experimentally studied at the Glenn Research Center in the late 60's and early 70's. A series of papers were written on the spinning ball contact. Townsend, Dietrich, and Zaretsky (1969) included speed effects on ball spinning torque. Allen and Zaretsky (1970) proposed a microasperity model for the elastohydrodynamic lubrication of a spinning ball on a flat surface. Dietrich, Parker, and Zaretsky (1968) studied the effect of ball-race conformity on spinning friction. Townsend and Zaretsky (1970) studied the effects on ball spinning torque of antiwear and extremepressure additives in a synthetic paraffinic lubricant.

The purpose of this work was to design, construct and operate a totally passive, permanent magnetic bearing rig to demonstrate its potential for spacecraft applications. The design incorporated permanent magnetic bearings, operating in the repulsive mode for radial bearing support, and jewel bearings for axial support.

\section{EXPERIMENTAL}

\section{DESIGN AND CONSTRUCTION}

A photo image and a schematic view of the permanent magnetic bearing rig are shown in Figures 1 and 2. The support base is made of a single piece of aluminum alloy. The rest of the rig consists of two permanent magnetic bearings, a wheel, jewel bearings on both ends of the rotor, and an air impeller. The two sets of permanent magnetic bearings operating in the repulsion mode provide levitation in the radial direction. The axial movement of the rotor is constrained by two jewel bearings that were placed on both ends of the rotor to allow for force reversal.

The rotor shaft was made of nonmagnetic stainless steel. The wheel, permanent magnetic bearings and an air impeller were slip fit over the rotor shaft and restrained axially by retaining rings. Each end of the rotor has a ball retainer to hold the $3.175 \mathrm{~mm}(0.125 \mathrm{inch})$ diameter ball used in the jewel bearing. The ball retainer is held to the rotor by threads on the rotor bore. The arrangement of components on the rotor is shown in Figure 3.

Figure 4 depicts the permanent magnet bearing assembly. The magnets were axially magnetized, meaning the poles are on the flat sides the magnets. A separate magnet stack was attached to the rotor and to the stator. Four magnet rings comprise each magnet stack. The poles of the magnets were oriented so that the stationary magnets and the rotating magnets repel each other when the non-rotating and the rotating sleeves are axially aligned. 
Neodymium-iron-boron $(\mathrm{NdFeB})$ magnets were used, having a nominal $\mathrm{BH}$ product of 35 MGOe (Gauss-Oersted $\times 10^{6}$ ). The dimensions of the rotating and stationary magnets are as follows. The OD (outside diameter) of the rotating magnet is $45.7 \mathrm{~mm}$ (1.800 in) and the ID (inside diameter) is $31.8 \mathrm{~mm}$ (1.250 in). The stationary magnet OD is $61.0 \mathrm{~mm}$ (2.400 in) and the ID is $48.3 \mathrm{~mm}$ (1.900 in). The thickness of magnet rings used in both stacks is $5.08 \mathrm{~mm}$ (0.200 inch). Therefore, the total axial thickness of the magnets in each stack is nominally $20.3 \mathrm{~mm}(0.800 \mathrm{inch})$.

Both the non-rotating and the rotating sleeves were made of nonmagnetic stainless steel. The stacks of magnets and the nonconductive spacers were connected together with epoxy in their mounting sleeve. The magnets were stacked with like poles adjacent to each other (NSSN-NS-SN) and permanently locked in place with epoxy. During the assembly process each magnet was coated with epoxy and put in the sleeve along with the nonconductive spacers and the sleeve end ring. An arbor press was used to provide the force to hold the magnets in the sleeve while press pins could be installed in the sleeve end ring. Once the sleeves were assembled, a thin coat of epoxy was also applied to the free surface of the magnets to prevent the magnets from oxidizing.

The OD of the nonrotating magnet sleeve was threaded. These threads fit the threading along the rotor axis of the support base, allowing the stator magnets to be moved axially. The stator magnet sleeve was rotated by inserting a $\varnothing 4.75 \mathrm{~mm}$ rod into a hole on the end of this sleeve. The rod was turned until the stationary sleeve was positioned over the rotating sleeve. The stator magnets were adjusted to minimize the axial force before operation.

The rotating and stationary magnets had a nominal $1.27 \mathrm{~mm}(0.05 \mathrm{inch})$ radial gap. The nonconductive spacers on the rotor and the stator were axially aligned and have a $0.76 \mathrm{~mm}$ (0.03 inch) nominal gap. This smaller clearance was to prevent the rotor and stator magnets from contacting during installation and operation.

A schematic of the jewel bearing assembly is shown in Figure 5. The jewel bearing on each end of the rotor consisted of a removable $3.175 \mathrm{~mm}(0.125 \mathrm{inch})$ diameter $\mathrm{Si}_{3} \mathrm{~N}_{4}$ ball held in the ball retainer in the center of the rotor shaft. About $0.50 \mathrm{~mm}(0.02 \mathrm{inch})$ of the ball extends beyond the surface of the ball retainer. The ball spins against the stationary 440C stainless steel disk of the jewel bearing. The surface of the disk was perpendicular to the axis of the rotor. A piezoelectric load cell measured the load of the jewel bearing contact.

An air impeller drives the shaft. The air impeller is a disk with blind holes drilled on both sides. One air stream is directed to either side of the disk to minimize the radial force on the rotor. The blind holes catch the air, and rotate the rotor.

\section{SPIN TESTING}

The rotor was spun using an air impeller. A 120-psig-air line was connected to a pressure regulator leading to the air impeller. Adjusting the flow rate of the compressed air against the impeller could control the rotational speed of the bearing. A stroboscope was used to monitor the rotational speed.

Testing was conducted by slowly increasing the speed. The speed was gradually increased to $5500 \mathrm{rpm}$ and the bearing ran very smoothly over the entire speed range. It was stopped at this point only because of the loud noise generated by the compressed air. 
The rotor passed through a critical speed at $3336 \mathrm{rpm}$, but no resonant vibrations were observed. This critical speed was found by impact testing of the rotor and is discussed later in the paper. The tests were repeated a second time and again no vibrations were observed.

\section{RESULTS AND DISCUSSION}

\section{RADIAL AND AXIAL STIFFNESSES OF BEARINGS}

The procedure for experimentally measuring the radial magnetic bearing stiffness was to direct the axial force to one jewel bearing by adjusting the magnetic bearing stators. The disk part of the jewel bearing at the other end of the rotor was removed so that the rotor was free to rotate about the contacting jewel bearing. Two dial indicators were contacted against the shaft to measure the radial deflection. One dial indicator was positioned $40 \mathrm{~mm}$ from the free end of the rotor. The other dial indicator was positioned $25 \mathrm{~mm}$ from the contacting jewel bearing. The rotor was deflected by adding weights to the shaft near the free end. The deflections of both dial indicators were recorded as a function of applied load. The moments about the existing jewel bearing were computed for each load applied and these were used to calculate the stiffness of the passive magnetic bearings. Analysis of the two dial indicator readings showed that the ball of the jewel bearing was not laterally displaced when the weights were loaded on the rotor. The force versus deflection characteristics of one passive magnetic bearing was calculated from the load versus deflection curve.

To predict the stiffness of the permanent magnetic bearing by the finite element method, a finite element model was made for the permanent magnet rings. The model had 77760 linear brick elements as shown in Figure 6. A magnetostatic solver was used to compute the distribution of the magnetic field. The Maxwell stress tensor was integrated over the surface of the four inner ring magnets to calculate the force on them.

Figure 7 shows the displacement as a function of radial load for the finite element and experimental data. In order to compare the experimental and the finite element results, linear regression curve fits were performed. The slope of the experimental curve is $1.78 \times 10^{5} \mathrm{~N} / \mathrm{m}$ $\left(1.02 \times 10^{3} \mathrm{lb}_{\mathrm{f}} / \mathrm{in}\right)$. The slope of the finite element curve is $1.87 \times 10^{5} \mathrm{~N} / \mathrm{m}\left(1.07 \times 10^{3} \mathrm{lb} / \mathrm{in}\right)$. The radial stiffness found by the experimental method is about 5.2 percent less than the finite element prediction which was considered very good agreement.

The radial stiffness per unit length of the magnet stack of each bearing was calculated by dividing the experimental radial stiffness, $1.78 \times 10^{5} \mathrm{~N} / \mathrm{m}\left(1.02 \times 10^{3} \mathrm{lb} / \mathrm{in}\right)$ by the length of each magnet stack, $20.3 \mathrm{~mm}(0.800 \mathrm{in})$. This value is $8.76 \times 10^{6}(\mathrm{~N} / \mathrm{m}) / \mathrm{m}\left(1.27 \times 10^{3}\left(1 \mathrm{~b}_{\mathrm{f}} / \mathrm{in}\right) / \mathrm{in}\right)$.

To measure the axial stiffness, one non-rotating magnetic bearing sleeve was rotated by means of the threading in the support base. This caused the magnet stacks to become axially displaced relative to each other. This axial displacement was measured with a dial indicator. The axial load due to this displacement was measured with the load cell positioned behind the disk of the jewel bearing. This procedure was repeated for a number of different displacements and the data plotted in Figure 8. The figure shows that the axial load is a linear function of displacement for this permanent magnetic bearing. A linear regression fit of the curve gave a value of $3.52 \times 10^{5} \mathrm{~N} / \mathrm{m}\left(2.01 \times 10^{3} \mathrm{lb}_{\mathrm{f}} / \mathrm{in}\right)$ for the axial stiffness of one bearing.

Application of Earnshaw's theorem implies that the axial stiffness should be exactly twice the radial stiffness. Comparing the experimental axial stiffness of Figure $8\left[3.52 \times 10^{5}\right.$ $\left.\mathrm{N} / \mathrm{m}\left(2.01 \times 10^{3} \mathrm{lb}_{\mathrm{f}} / \mathrm{in}\right)\right]$ to twice the experimental radial stiffness of Figure $7\left[1.78 \times 10^{5} \mathrm{~N} / \mathrm{m}\right.$ 
$\left(1.02 \times 10^{3} \mathrm{lb}_{\mathrm{f}} / \mathrm{in}\right)$ ] showed that the 2 to 1 ratio predicted by Earnshaw's theorem is within 1.1 percent which is considered excellent agreement.

\section{DAMPING}

The procedure for measuring the free vibration history of the rotor was as follows. An axial force on one of the jewel bearings was produced by misalignment of the stationary magnets and then rotating magnets of the magnetic bearing. The disk of the jewel bearing at the unloaded end of the rotor was removed so that the rotor was free to move about this end.. An accelerometer was attached to the rotor $25 \mathrm{~mm}$ from the free end. To excite the rotor, the wheel was struck radially with an impact hammer. Figure 9 gives the radial free vibration history of the rotor as a function of time. The rotor was "pinned" against only one jewel bearing since during operation only one jewel bearing is in contact. These conditions resulted in only one mode, not a bounce and a tilt mode as would occur with "free-free" boundary conditions.

A radial damping coefficient was calculated from the logarithmic decrement and from the half-power bandwidth methods. The natural logarithm of consecutive amplitude ratios is called the logarithmic decrement, $\delta$, equaling $\ln \left(\mathrm{x}_{1} / \mathrm{x}_{2}\right)$, where $\mathrm{x}_{1}$ and $\mathrm{x}_{2}$ are consecutive peak amplitudes. The log decrement is a measure of the damping factor $\xi$ and it gives a convenient method to measure the damping in a system. The damping coefficient is related to the $\log$ decrement, by $\delta=2 \pi \xi /\left(1-\xi^{2}\right)^{0.5}$. Taking the log decrement of the first five peaks in the time domain gives $\xi=0.0649$, or about 6.5 percent damping. The radial frequency response of the rotor is shown in Figure 10. The first fundamental occurred at $55.6 \mathrm{~Hz}$ (3336 rpm). From the frequency response data, the damping coefficient of the first fundamental was calculated by the half-power bandwidth method. The damping coefficient of the first fundamental was found to be 0.069 , close to the damping coefficient as found by the logarithmic decrement method. Since no vibrations were observed on running the bearing through the critical speed, 6.5 percent damping is adequate to control the rotor.

\section{PRESENT AND FUTURE WORK}

This work was led by Robert Fusaro who was able to obtain funding from the Glenn Research Center Director's Discretionary Fund. This work will serve as the basis to hopefully convince the Discretionary Fund Committee to continue further funding in the area of magnetic bearings. If funded, the magnetic bearing rig will be tested at higher rotational speeds, up to $50,000 \mathrm{rpm}$, to assess vibration problems which are of great concern if magnetic bearings are to be used in spacecraft. Another area of concern is the successful use of mechanical back-up bearings that are simple in design, small in size, and capable of absorbing the high rotational energy of the magnetic bearing without serious damage.

\section{SUMMARY OF RESULTS}

A totally passive, permanent magnetic bearing rig was designed, constructed, and tested. Support of the rotor was accomplished in the radial direction by two sets of permanent magnetic bearings and in the axial direction by two sets of jewel bearings. The following results were obtained. 
1. The rig was successfully operated to a speed of $5500 \mathrm{rpm}$, which was 65 percent above the first critical speed.

2. The radial stiffness of one magnetic bearing was measured to be $1.78 \times 10^{5} \mathrm{~N} / \mathrm{m}$ $\left(1.02 \times 10^{3} \mathrm{lb}_{\mathrm{f}} / \mathrm{in}\right)$ which was within 5 percent of a finite element prediction. The measured stiffness was adequate for the currently designed rotor.

3. The fact that experimental and finite element methods predictions agree demonstrate that finite element methods can be used to accurately design the size and number of the magnets for the radial support of the bearings. The radial damping for the first fundamental was measured to be 6.5 percent of critical damping. This was adequate damping to pass through the first critical speed.

4. The axial stiffness was measured and was shown to be within 1 percent of twice the measured radial stiffness. This is consistent with Earnshaw's theorem.

\section{REFERENCES}

Allen, C.W., Zaretsky, E.V., 1970, "Microasperity Model for Elastohydrodynamic Lubrication of a Spinning Ball on a Flat Surface," NASA TN D-6009.

Dietrich, M.W., Parker, R.J., Zaretsky, E.V., 1968, "Effect of Ball-Race Conformity on Spinning Friction," NASA TN D-4669.

Fremerey, J.K., 2000, "A 500-Wh Power Flywheel on Permanent Magnet Bearings," Fifth International Symposium on Magnetic Suspension Technology, pp. 287-295.

Jansen, R., DiRusso, E., 1996, "Passive Magnetic Bearing with Ferrofluid Stabilization," NASA TM-107154.

Ohji, T., Mukhopadhyay, S.C., Iwahara, and Yamada, S., 1999, "Permanent Magnet Bearings for Horizontal- and Vertical-Shaft Machines: A Comparative Study," Journal of Applied Physics, Vol. 31, 8, pp. 4648-4650.

Sankar, T.S., and Tzenov, P.I., 1994a, "Friction and Motion Accuracy in Jewel Bearing," Tribology Transactions, Vol. 37, 2, pp. 269-276.

Sankar, T.S., and Tzenov, P.I., 1994b, "The Steady-State Dynamics of Jewel Bearing with a Free Ball," Tribology Transactions, Vol. 37, 2, pp. 403-409.

Satoh, I., Shirao, Y., and Kanemitsu, Y., 1996, "Dynamics and Vibration of a Single Axis Active Magnetic Bearing System for Small-Sized Rotating Machinery," Fifth International Symposium on Magnetic Bearings, pp. 497-502.

Siebert, M., Ebihara, B., Jansen, R., Fusaro, R.L., Morales, W., Kasak, A., and Kenny, A., 2002, "A Passive Magnetic Bearing Flywheel," NASA TM-2002-211159, 2002.

Townsend, D.T., and Zaretsky, E.V., 1970, "Effects of Antiwear and Extreme-Pressure Additives in a Synthetic Paraffinic Lubricant on Ball Spinning Torque," NASA TN D-5820.

Townsend, D.P., Dietrich, M.W., Zaretsky, E.V., 1969, "Speed Effects on Ball Spinning Torque," NASA TN D-5527. 


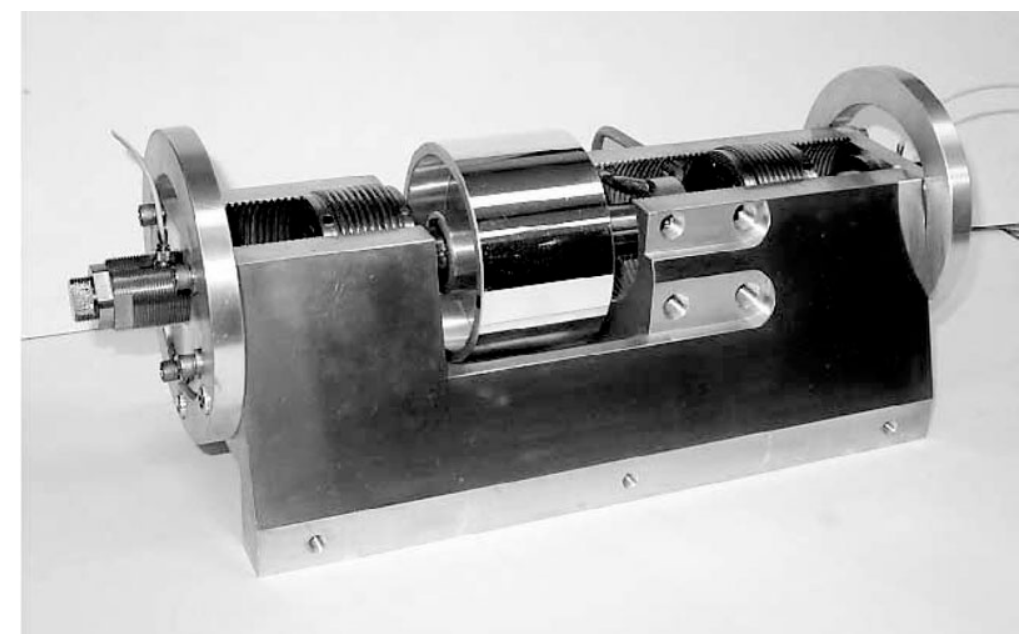

Figure 1.-Photographic image of the magnetic bearing rig.

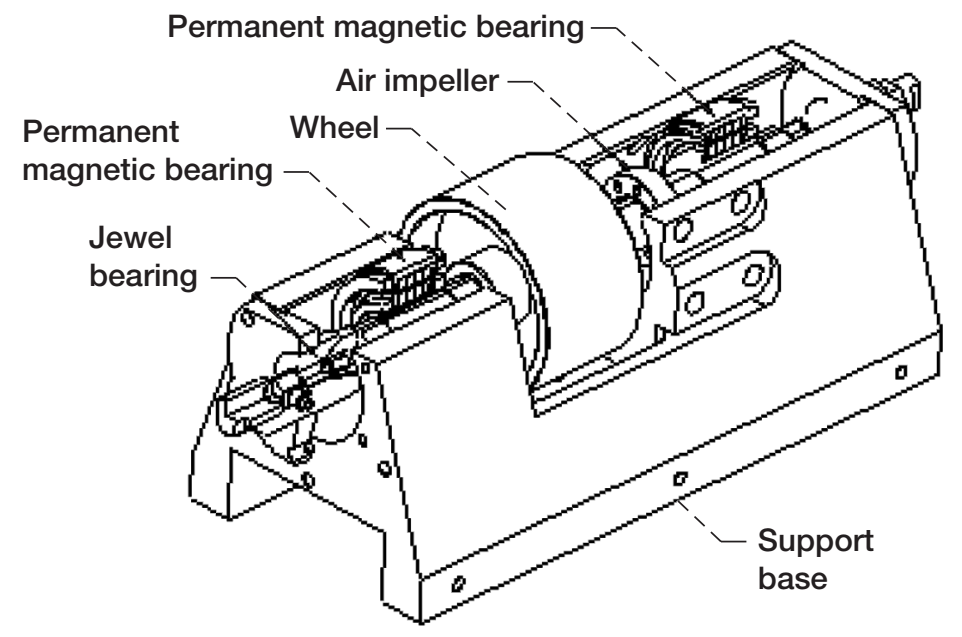

Figure 2.-Schematic view of magnetic bearing rig. The permanent magnetic bearings and jewel bearing assembly at the near end were sectioned for clarity. 


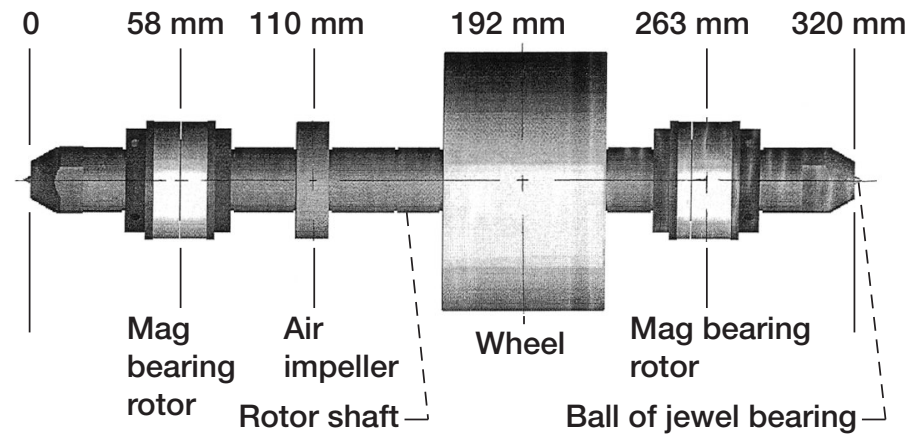

Figure 3.-Schematic of rotor that shows the location of components. The total mass of the rotor is $2.26 \mathrm{~kg}$. The diameter of the wheel is $102 \mathrm{~mm}$.

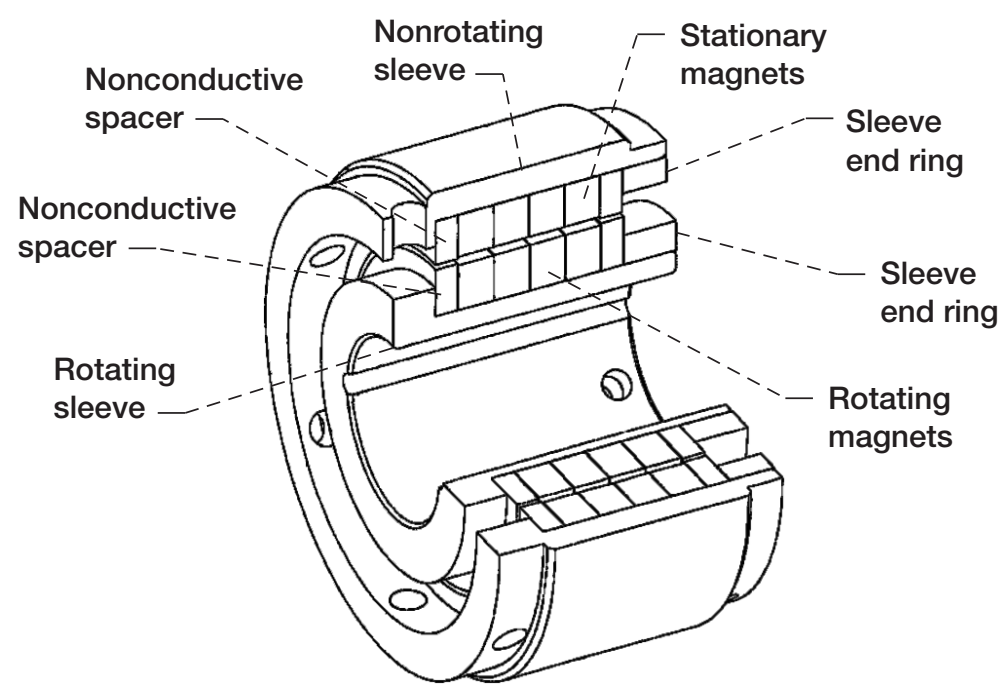

Figure 4.- Sectioned view of permanent magnetic bearing assembly. There are two of these assemblies attached to the rotor. 


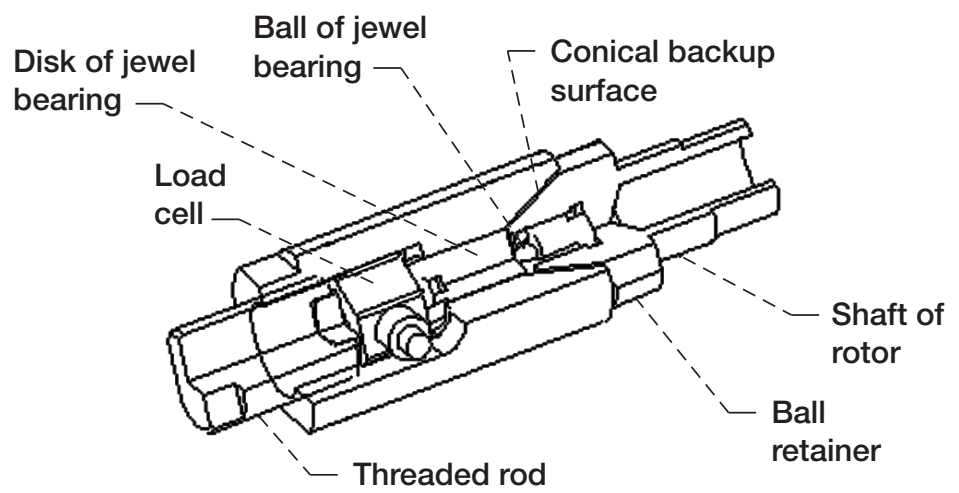

Figure 5.-Jewel bearing assembly applied to each end of the rotor. The ball of the jewel bearing rotates against the stationary disk of the jewel bearing during operation.

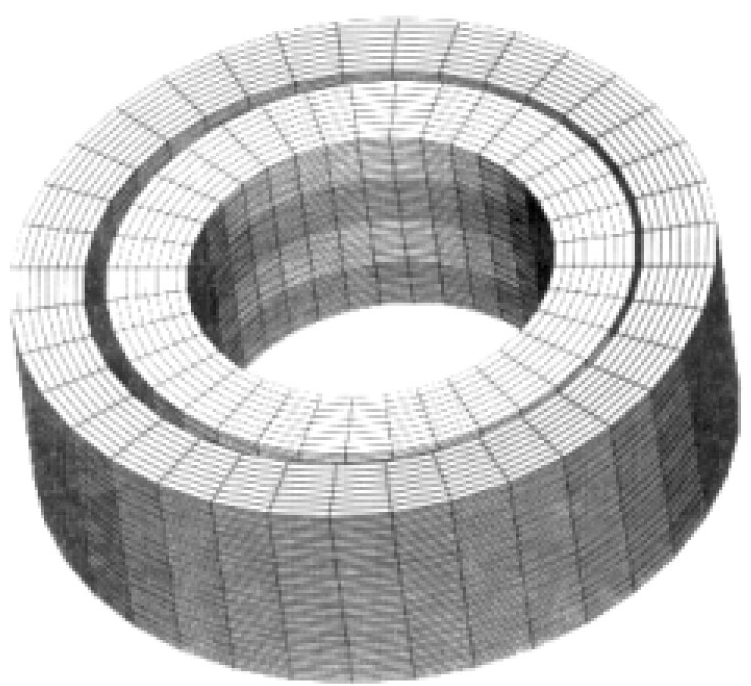

Figure 6.-Finite element model of ring magnets in magnetic bearing. 


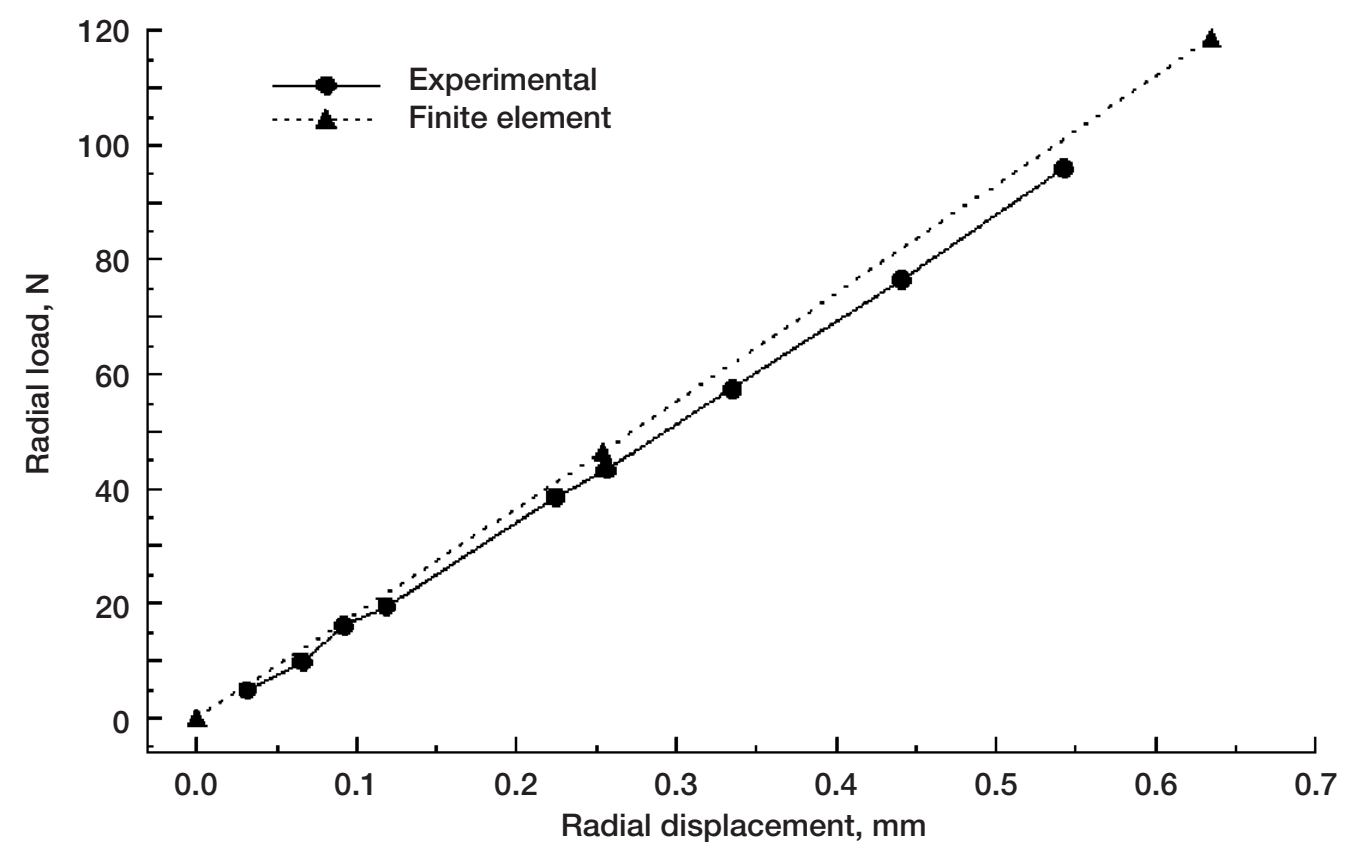

Figure 7.-Radial displacement as a function of radial load for one permanent magnetic bearing as determined by experimental testing and finite element analysis.

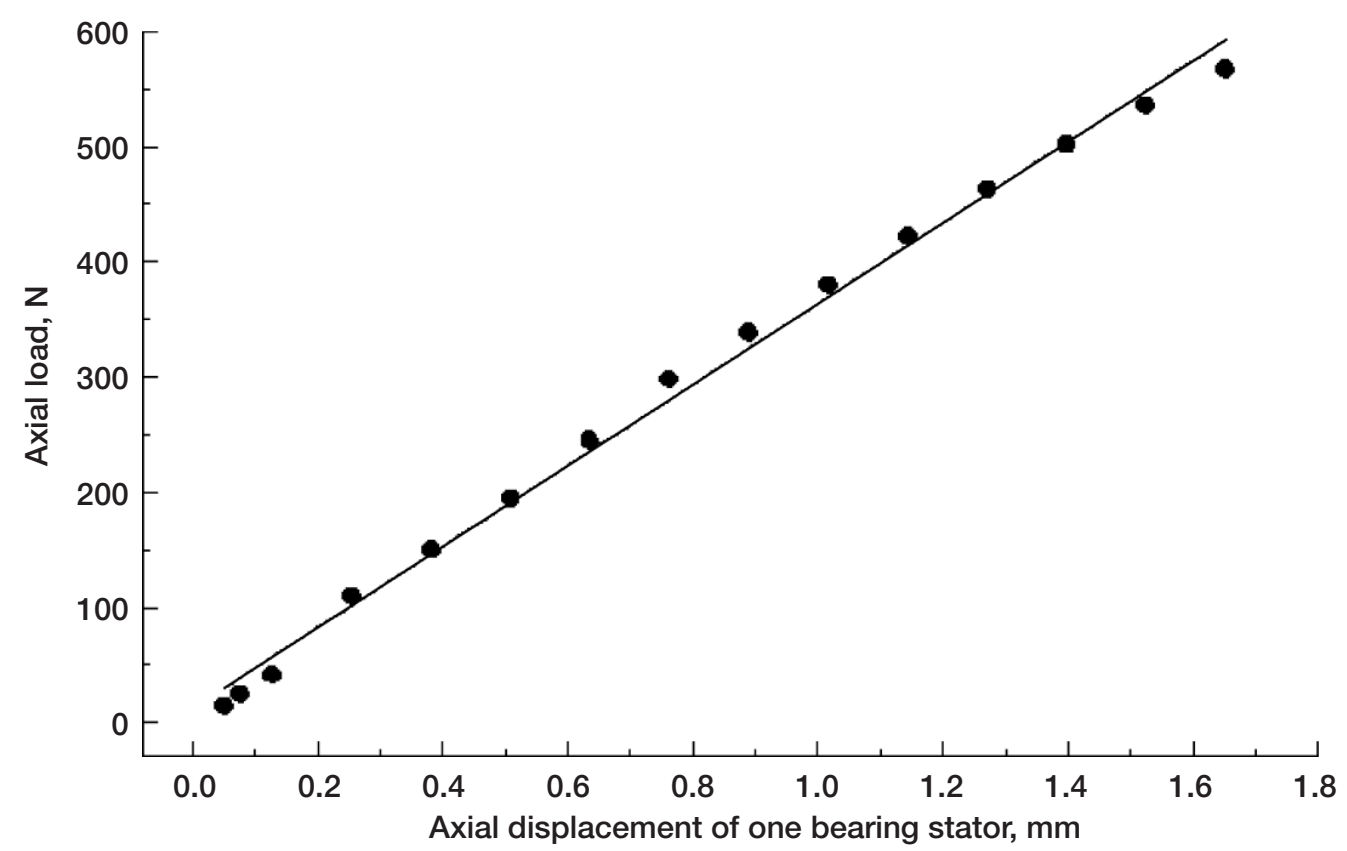

Figure 8.-Axial displacement as a function of axial load for one magnetic-bearing stator of the permanent magnetic bearing. 


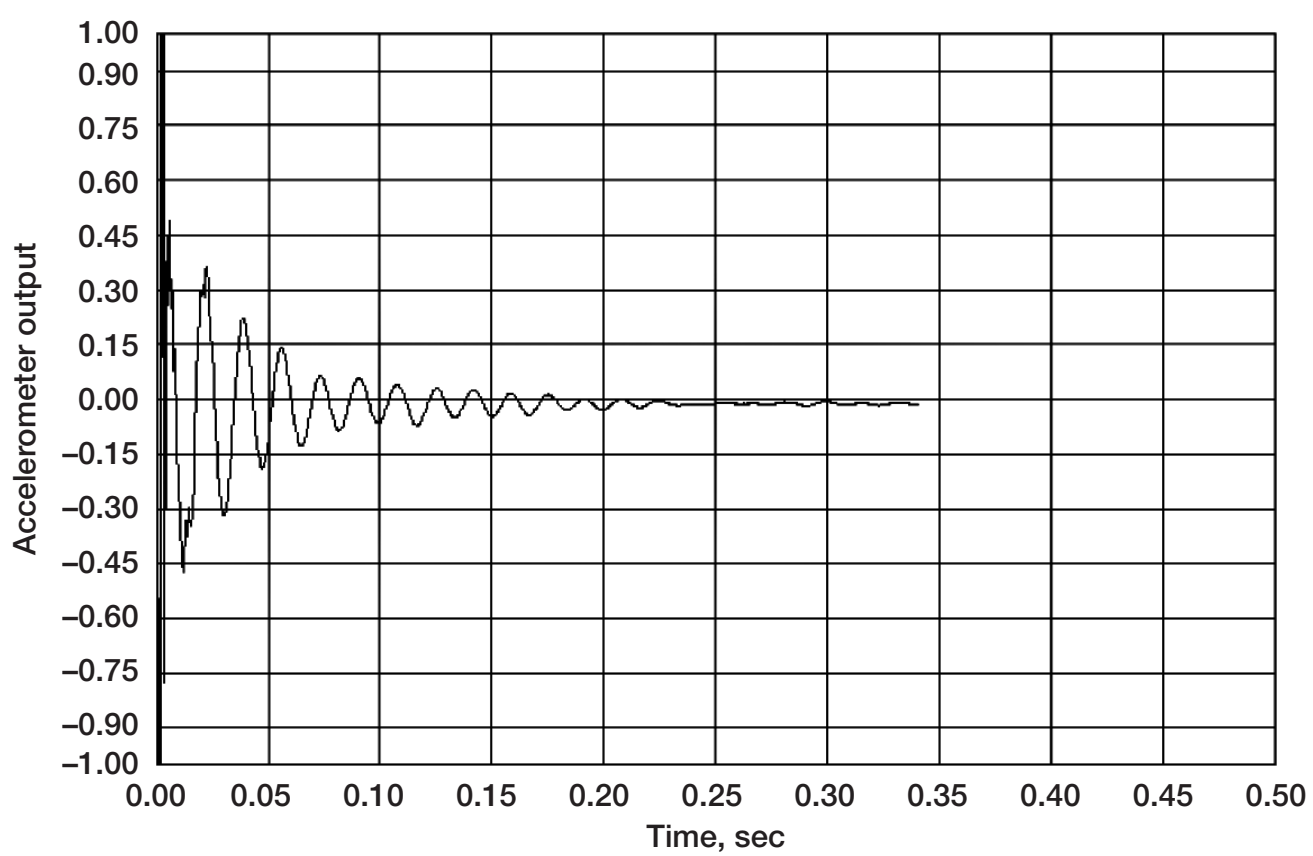

Figure 9.-Radial free vibration history of the rotor from an impact test. The vertical axis is the output of the accelerometer attached to the free end of the rotor.

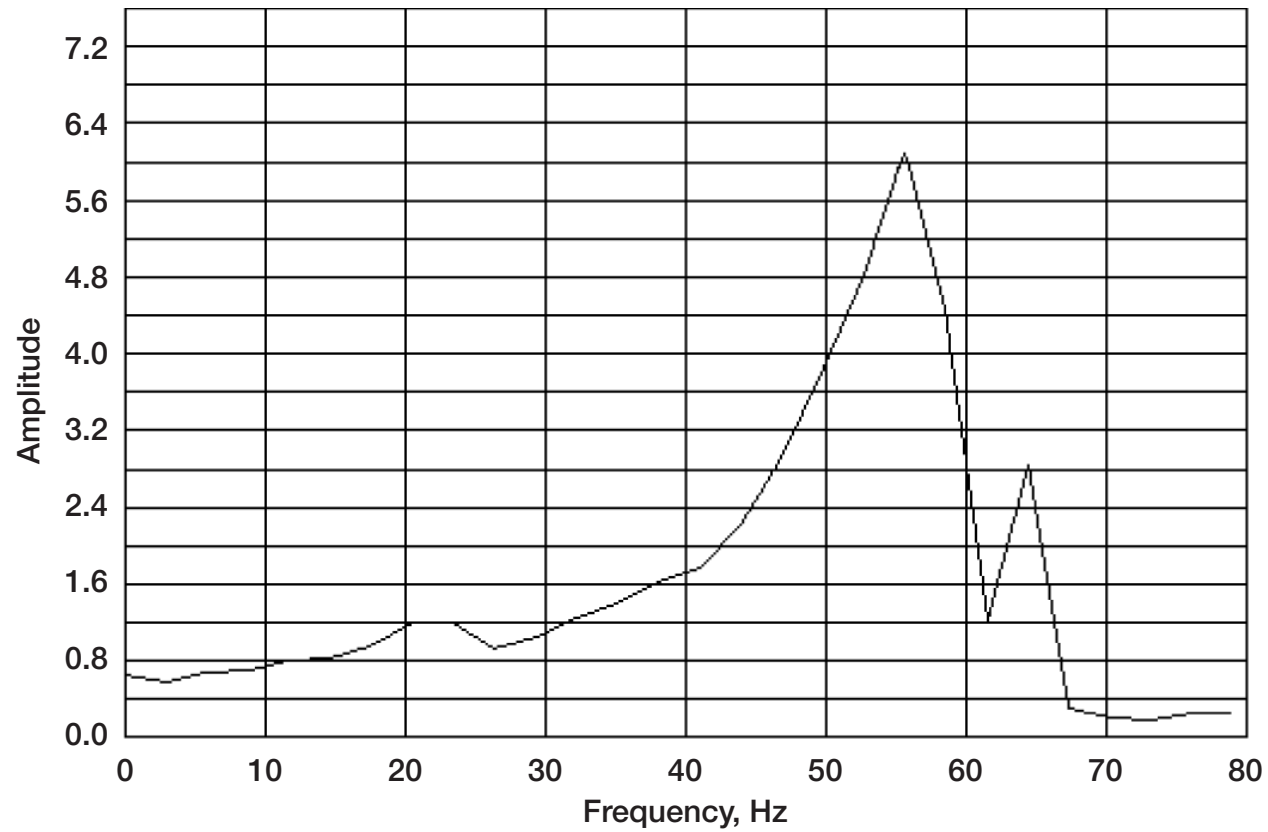

Figure 10.-Frequency response of the rotor that occurred from impact test. 


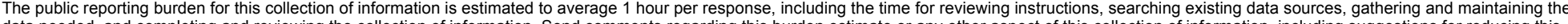

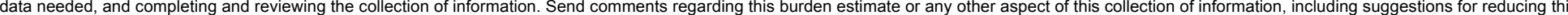

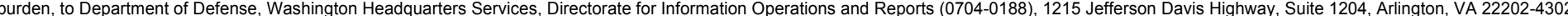

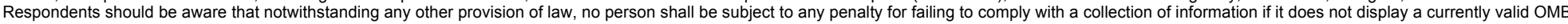
control number.

PLEASE DO NOT RETURN YOUR FORM TO THE ABOVE ADDRESS.
1. REPORT DATE (DD-MM-YYYY)
2. REPORT TYPE
3. DATES COVERED (From - To)

01-01-2008

\section{TITLE AND SUBTITLE}

Technical Memorandum

Permanent Magnetic Bearing for Spacecraft Applications

5b. GRANT NUMBER

5c. PROGRAM ELEMENT NUMBER

\section{AUTHOR(S)}

Morales, Wilfredo; Fusaro, Robert; Kascak, Albert

\section{5d. PROJECT NUMBER}

5e. TASK NUMBER

5f. WORK UNIT NUMBER

WBS-22-708-90-01

8. PERFORMING ORGANIZATION REPORT NUMBER

E-13668-1

National Aeronautics and Space Administration

John H. Glenn Research Center at Lewis Field

Cleveland, Ohio 44135-3191

9. SPONSORING/MONITORING AGENCY NAME(S) AND ADDRESS(ES)

National Aeronautics and Space Administration

Washington, DC 20546-0001

\section{SPONSORING/MONITORS ACRONYM(S) \\ NASA}

11. SPONSORING/MONITORING REPORT NUMBER

NASA/TM-2003-211996-REV1

\section{DISTRIBUTION/AVAILABILITY STATEMENT}

Unclassified-Unlimited

Subject Categories: 18 and 20

Available electronically at http://gltrs.grc.nasa.gov

This publication is available from the NASA Center for AeroSpace Information, 301-621-0390

\section{SUPPLEMENTARY NOTES}

\section{ABSTRACT}

A permanent, totally passive magnetic bearing rig was designed, constructed, and tested. The suspension of the rotor was provided by two sets of radial permanent magnetic bearings operating in the repulsive mode. The axial support was provided by jewel bearings on both ends of the rotor. The rig was successfully operated to speeds of $5500 \mathrm{rpm}$ using an air impeller. Radial and axial stiffnesses of the permanent magnetic bearings were experimentally measured and then compared to finite element results. The natural damping of the rotor was measured and a damping coefficient was calculated.

\section{SUBJECT TERMS}

Magnetic bearings; Jewel bearings; Space vehicles; Aerospace; Spacecraft

\section{SECURITY CLASSIFICATION OF:}

a. REPORT

$\mathrm{U}$

\section{b. ABSTRACT}

$\mathrm{U}$

\section{LIMITATION OF} ABSTRACT

UU
18. NUMBER

PAGES

17 19a. NAME OF RESPONSIBLE PERSON

STI Help Desk (email:help@sti.nasa.gov)

19b. TELEPHONE NUMBER (include area code) $301-621-0390$ 

